\title{
Oculomotor Nerve Palsy following Cardiac Tamponade with Churg-Strauss Syndrome: A Case Report
}

\author{
Kazuki Suganuma ${ }^{a}$ Takao Hashimoto $^{a}$ Hiromasa Sato $^{a}$ \\ Tomohiro Suzuki $^{b}$ Shunpei Sakurai ${ }^{b}$ \\ Departments of ${ }^{\mathrm{a}}$ Neurology and ${ }^{\mathrm{b}}$ Cardiology, Aizawa Hospital, \\ Matsumoto, Japan
}

\section{Key Words}

Churg-Strauss syndrome $\cdot$ Oculomotor nerve palsy · Cardiac tamponade ·

Corticosteroid

\begin{abstract}
A 57-year-old man with a history of more than 10 years of bronchial asthma and chronic sinusitis complained of double vision which developed 18 days after cardiac tamponade with eosinophil-rich fluid (eosinophils 30\%). He had oculomotor nerve palsy, and a blood test revealed eosinophilia $\left(12,700 / \mathrm{mm}^{3}\right)$ and elevation of both C-reactive protein and rheumatoid factor. He was diagnosed as having Churg-Strauss syndrome. His symptoms were relieved by corticosteroid therapy. Our case and previous cases in the literature revealed that oculomotor nerve palsy in Churg-Strauss syndrome is associated with pupil involvement and may be relieved by corticosteroid treatment.
\end{abstract}

\section{Introduction}

Churg-Strauss syndrome (CSS) is a form of systemic vasculitis characterized by bronchial asthma, eosinophilia and necrotizing vasculitis [1]. CSS affects many organs such as the skin, kidneys, nerves, and lungs. Peripheral nerve involvement is common in CSS, but cranial nerve involvement is rare [2-4]. We present a case with CSS who developed oculomotor nerve palsy. 


\section{Case Report}

A 57-year-old Japanese man was admitted to our cardiology department complaining of dyspnea and fever that had developed 2 weeks prior to admission. He had a history of more than 10 years of bronchial asthma and sinusitis; his family history was unremarkable with regard to bronchial asthma and diabetes mellitus. His physical examination on admission revealed a body temperature of $38.5^{\circ} \mathrm{C}$, a blood pressure of $117 / 73 \mathrm{~mm} \mathrm{Hg}$ and a heart rate of 141 beats/min. Routine laboratory data demonstrated an increased white blood cell count of $14,990 / \mathrm{mm}^{3}$ (eosinophils $29.4 \%$ ), lactate dehydrogenase 282 IU/l (normal 115-245), creatine kinase 99 IU/l (normal 12-142) and C-reactive protein (CRP) $9.2 \mathrm{mg} / \mathrm{dl}$ (normal <0.3). A subsequent transthoracic echocardiogram showed a large circumferential pericardial effusion and a small amount of bilateral pleural effusion. The patient was diagnosed as having cardiac tamponade associated with pneumonia, and daily intravenous administration of $6 \mathrm{~g}$ sulbactam/ampicillin was initiated. Pericardiocentesis was performed, and $580 \mathrm{ml}$ of yellowish fluid was extracted. Examination of the pericardial fluid revealed a white blood cell count of 17,625/mm (eosinophils 30\%), total protein $5.5 \mathrm{~g} / \mathrm{dl}$ (serum total protein $6.4 \mathrm{~g} / \mathrm{dl}$ ) and glucose $61 \mathrm{mg} / \mathrm{dl}$ (serum glucose $116 \mathrm{mg} / \mathrm{dl}$ ). His dyspnea resolved after drainage, and his CRP level decreased to $3.9 \mathrm{mg} / \mathrm{dl} 13$ days after admission.

The patient developed double vision and a left ptosis 18 days after pericardiocentesis. He was diagnosed with oculomotor nerve palsy and was moved to the neurology department. His physical examination revealed a body temperature of $36.3^{\circ} \mathrm{C}$, a blood pressure of $157 / 98 \mathrm{~mm} \mathrm{Hg}$ and a heart rate of 98 beats/min upon his transfer to the neurology department. Left-sided ptosis was observed, and the left pupil was dilated and non-reactive to light. The left eye was in an abductive position, and movement was limited except for abduction (fig. 1). Other cranial nerves were normal. There was hypesthesia in the right chest and the left thigh. Muscular strength and reflex were normal. Blood laboratory data demonstrated a white blood cell count of $20,100 / \mathrm{mm}^{3}$ (eosinophils $12,700 / \mathrm{mm}^{3}$, $63.2 \%$ ), lactate dehydrogenase $476 \mathrm{IU} / \mathrm{l}$, CRP $4.0 \mathrm{mg} / \mathrm{dl}$, rheumatoid factor $711.6 \mathrm{IU} / \mathrm{ml}$ (normal <20) and complement C3 $167 \mathrm{mg} / \mathrm{dl}$ (normal 86-160); myeloperoxidase-specific anti-neutrophil cytoplasmic antibody (MPO-ANCA), cytoplasmic staining anti-neutrophil cytoplasmic antibody and antinuclear antigen were all negative. Urinalysis was normal. The results of the cerebrospinal fluid examination were normal. A transthoracic echocardiogram showed a small amount of pericardial effusion and a small amount of bilateral pleural effusion. An MRI of the T2 and FLAIR sequences showed no abnormalities in the brain, including the brain stem, cavernous sinus and orbits.

He was diagnosed as having CSS, and was given a 3-day course of pulse therapy with $1 \mathrm{~g} /$ day methylprednisolone, followed by $50 \mathrm{mg} /$ day oral prednisolone. Ptosis, hypesthesia and eye movement improved along with pericarditis, and his eosinophil count and CRP level decreased to normal values 7 days after admission. The prednisolone dose was tapered over the following year, and remission was sustained with $3 \mathrm{mg} /$ day prednisolone. Mild downward gaze palsy on the left side was sustained for more than 1 year.

\section{Discussion}

The criteria for CSS according to the American College of Rheumatology [5] include asthma, eosinophilia, extravascular eosinophilic involvement, neuropathy, sinus abnormality and pulmonary infiltrate, and our patient fulfilled the first five conditions. MPO-ANCA was not elevated in our patient, but its positive rate in CSS has been reported to be $60-70 \%[6]$.

The first manifestation of CSS in our patient was cardiac tamponade. Pericardial effusion has been found in 22-32\% of CSS cases [2,6], but severe pericarditis or cardiac tamponade as in our patient has rarely been reported [7, 8]. Our patient showed a negative MPO-ANCA, and it has been reported that cardiac manifestations are more common among ANCA-negative than ANCA-positive patients, the incidence ratios being 36 and 7\%, respectively [9]. ANCA may be relevant to organ vulnerability in CSS. 
Treatment with corticosteroids has been reported to be beneficial for pericarditis in CSS $[7,8]$.

In our patient, unilateral oculomotor nerve palsy followed cardiac involvement. Association of sensory disturbances in the body may have presented multiple mononeuropathy. Frequent etiologies of acquired oculomotor nerve palsy are intracranial aneurysms and tumors, meningeal lymphoma, diabetes mellitus, TolosaHunt syndrome, and others. Cranial nerve involvement is found in $3.1-16 \%$ of CSS patients: optic neuropathy is the most common $[2,4]$, but oculomotor nerve palsy is very rare. We found 4 detailed case reports of CSS patients manifesting oculomotor nerve palsy in the literature (see online suppl. table 1 ,

www.karger.com/doi/10.1159/000334127) [10-13]. The pupils were involved in all of the described cases, including our patient; this contrasts with diabetic oculomotor nerve palsy, in which the pupils are usually spared. The pupil involvement suggests that the damage to the oculomotor nerve in CSS is more severe than in diabetes, and this difference may be due to pathogenetic difference. With respect to associated symptoms, periorbital pain was not observed in all cases, contrasting with Tolosa-Hunt syndrome. Brain MRI was performed in 3 cases, including ours; it showed no abnormality in 2 cases and midbrain infarction in 1 case. No histological examination was carried out. Treatment with corticosteroids was successful in all of the described cases, but a partial paresis of the oculomotor nerve was sustained as a sequela in our patient.

In conclusion, CSS is one of the causative diseases of oculomotor nerve palsy. While the presence of periorbital pain is less frequent, the pupil is very often involved. Early initiation of corticosteroid is critical for a favorable outcome.

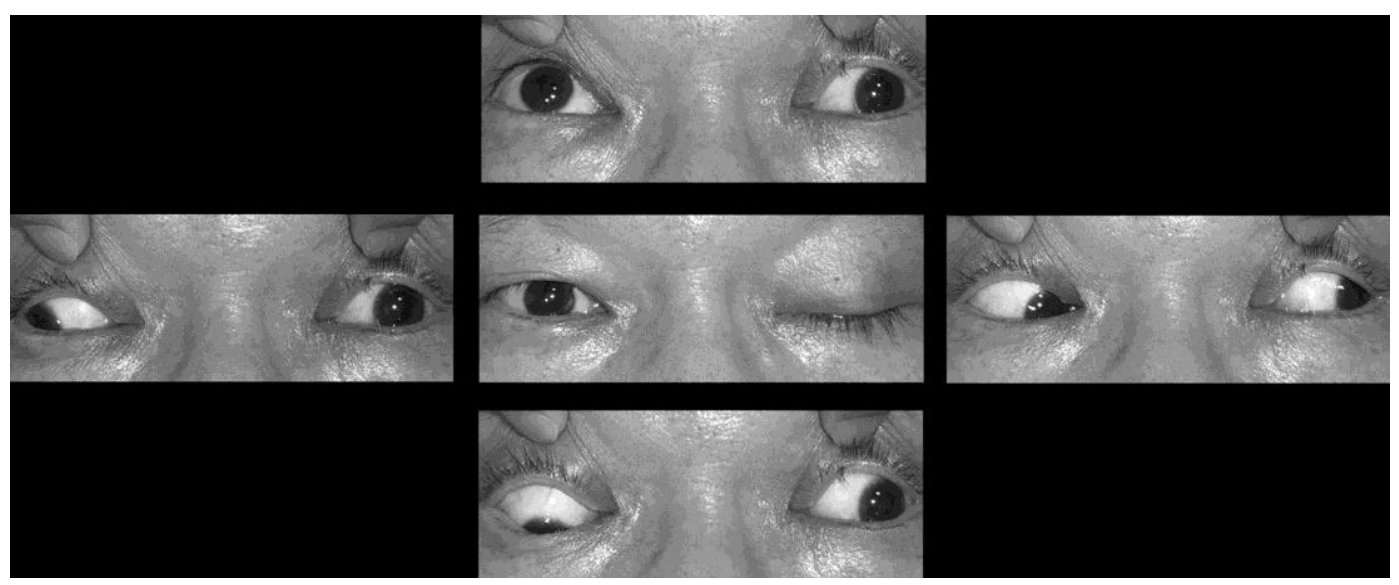

Fig. 1. Photographs of ocular positions showing complete left oculomotor nerve palsy associated with a severe ptosis and pupil dilatation. 


\section{References}

$>1$ Churg J, Strauss L: Allergic granulomatosis, allergic angitis, and periarteritis nodosa. Am J Pathol 1951;27:277-301.

-2 Solans R, Bosch JA, Pérez-Bocanegra C, Selva A, Huguet P, Alijotas J, Orriols R, Armadans L, Vilardell M: Churg-Strauss syndrome: outcome and long-term follow-up of 32 patients. Rheumatology 2001;40:763771.

-3 Guillevin L, Cohen P, Gayraud M, Lhote F, Jarrousse B, Casassus P: Churg-Strauss syndrome. Clinical study and long-term follow-up of 96 patients. Medicine 1999;78:26-37.

4 Della Rossa A, Baldini C, Tavoni A, Tognetti A, Neglia D, Sambuceti G, Puccini R, Colangelo C, Bombardieri S: Churg-Strauss syndrome: clinical and serological features of 19 patients from a single Italian centre. Rheumatology 2002;41:1286-1294.

5 Masi AT, Hunder GG, Lie JT, Michel BA, Bloch DA, Arfend WP, Calabrese LH, Edworthy SM, Fauci AS, Leavitt RY, et al: The American College of Rheumatology 1990 criteria for the classification of ChurgStrauss syndrome (allergic granulomatosis and angiitis). Arthritis Rheum 1990;33:1094-1100.

-6 Guillevin L, Visser H, Noel LH, Purrat J, Vermier I, Gayraud M, Oksman F, Lesavre P: Antineutrophil cytoplasm antibodies in systemic polyarteritis nodosa with and without hepatitis B virus infection and Churg-Strauss syndrome - 62 patients. J Rheumatol 1993;20:1345-1349.

7 Agard C, Rendu E, Leguern V, Ponge T, Masseau A, Barrier JH, Trochu JN, Hamidou MA, Guillevin L: Churg-Strauss syndrome revealed by granulomatous acute pericarditis: two case reports and a review of the literature. Semin Arthritis Rheum 2007;36:386-391.

$>8$ Ovadia S, Drir I, Zubkov T, Tanay A, Levy D, Zandman-Goddard G: Churg-Strauss syndrome: a rare presentation with otological and pericardial manifestations: case report and review. Clin Rheumatol 2009;28(suppl 1):S35-S38.

-9 Sablé-Fourtassou R, Cohen P, Mahr A, Pagnoux C, Mouthon L, Jayne D, Blockmans D, Cordier JF, Delaval P, Puechal X, Lanque D, Vaillard JF, Zoulim A, Guillavin L: Antineutrophil cytoplasmic antibodies and the Churg-Strauss syndrome. Ann Intern Med 2005;143:632-638.

-10 Abe-Matsuura Y, Fujimoto W, Arata J: Allergic granulomatosis (Churg-Strauss) associated with cutaneous manifestations: report of two cases. J Dermatol 1995;22:46-51.

11 Shintani S, Tsuruoka S, Yamada M: Churg-Strauss syndrome associated with third nerve palsy and mononeuritis multiplex of the legs. Clin Neurol Neurosurg 1995;97:172-174.

-12 H Tsuda, Ishikawa H, Majima T, Sawada U, Mizutani T: Isolated oculomotor nerve palsy in Churg-Strauss syndrome. Intern Med 2005;44:638-640.

13 Naitoh T: A case of Churg-Strauss syndrome in which oculomotor paralysis developed (in Japanese). Nihon Kokyuki Gakkai Zasshi 2008;46:1003-1006. 